\title{
PYROLYSIS OF SOLID WASTE AND ITS COMPONENTS IN A LAB SCALE INDUCTION-HEATING REACTOR
}

\author{
Oscar Sosa Sabogal ${ }^{1, \star}$, Sylvie Valin ${ }^{1}$, Sébastien Thiery ${ }^{1}$ and Sylvain Salvador ${ }^{2}$ \\ ${ }^{1}$ University Grenoble Alpes, CEA, LITEN, DTBH, L2CS; 17 rue des Martyrs, Grenoble, 38000, France \\ ${ }^{2}$ Centre RAPSODEE, IMT Mines Albi, CNRS UMR 5302, Allée des sciences, Albi, 81013, France
}

Article Info:

Received:

22 February 2021

Revised:

22 April 2021

Accepted:

17 May 2021

Available online:

30 June 2021

Keywords:

Pyrolysis

Gasification

Solid waste

Induction heating

Waste derived fuel

\section{ABSTRACT}

The present study investigates the thermochemical conversion of Solid Recovered Fuel (SRF), represented by selected "model materials". A laboratory-scale induction heated device was specifically developed to achieve fast pyrolysis conditions close to those encountered in a fluidized bed reactor. The novel device can handle up to 5 grams of solid, allowing fast heating rates (near $70^{\circ} \mathrm{C} / \mathrm{s}$ ) and a homogeneous distribution of temperature all along the reactor. Pyrolysis tests of a SRF sample and four model materials (Polyethylene, Polyethylene Terephthalate, beech wood, cardboard) were performed at $800^{\circ} \mathrm{C}$. The yield and composition of the produced gas for each sample were determined. Experimental results will help to elucidate the relation between the initial components of waste derived fuels and the obtained reaction products.

\section{INTRODUCTION}

About 2.01 billion metric tons of municipal solid waste (MSW) are produced annually worldwide. By 2050, this quantity is expected to increase by up to $70 \%$ (Kaza et al., 2018). As of today, $66 \%$ of the produced waste is still dumped or landfilled, causing environmental and health risks. Current management policies try to reduce this share by focusing on prevention, reduction, and mechanical recycling. Other solid waste fractions that cannot be reused or recycled are increasingly used to produce waste derived fuels, offering an interesting alternative to conventional disposal methods. Refuse Derived Fuel (RDF) and Solid Recovered Fuel (SRF) are both produced from industrial and household wastes, the latter following specific criteria indicated in CEN/TS 15359 (Solid Recovered Fuels, 2006). Both fuels include combustible materials with high calorific values like plastics, textiles, wood, and elastomers (Garcés et al., 2016).

Among the available waste to energy technologies, gasification has received an increasing interest in the last years (Saghir et al., 2018). Gasification is a thermochemical process where carbonaceous feedstocks react above $700^{\circ} \mathrm{C}$, in presence of an oxidizing agent that is fed below the stoichiometric amount needed for total oxidation. The produced syngas can be directly burnt to produce energy and heat or, after cleaning, used in a synthesis process to produce biofuels or chemicals. This process offers some environmental advantages compared to landfilling or incineration. However, upscaling still presents some technical barriers (Centi \& Perathoner, 2020).

Pyrolysis is of great interest since it is considered here as the first stage of the gasification process. During this step, the feedstock decomposes in absence of oxygen, producing volatiles in the form of light permanent gases (such as $\mathrm{H}_{2}, \mathrm{CO}, \mathrm{CO}_{2}, \mathrm{CH}_{4}$, and $\mathrm{H}_{2} \mathrm{O}$ ), and condensable hydrocarbons (tar). The remaining solid residue is known as char. Those devolatilization products participate with the oxidizing agent in the gasification step, where cracking and reforming reactions produce syngas. Distribution and product yields are highly influenced by temperature, heating rate and residence time, features that are directly related to reactor configuration (Pasel \& Wanzl, 2003). Slow heating rates induce high residence times and favor char formation, while high heating rates and high temperatures favor gas products (Efika et al., 2018).

Even in the same process conditions, final products are also affected by the raw composition of the feedstock (Esmaeili et al., 2020). In previous pyrolysis/gasification studies, researchers have attempted to evaluate the influence of the feedstock using real samples of waste fuels (Efika et al., 2015; Hwang et al., 2014). However, the heterogeneous composition of waste at many levels (source, season, components, etc.), as well as the different operations to which it is subjected during the production of derived fuels, makes it really challenging to apply the results to other fuels that
* Corresponding author

Oscar Sosa Sabogal

email: oscar.sosasabogal@cea.fr
Detritus / Volume 15 - 2021 / pages 107-112

https://doi.org/xxxxxxxxxxxxxxxxxxxx

(c) 2021 Cisa Publisher. Open access article under CC BY-NC-ND license 
may contain different feed compositions.

In this regard, several authors have conducted studies of the individual typical components found in waste (Chhabra et al., 2020; Meng et al., 2015; Zhou, Long, et al., 2015), most of them by thermogravimetric analysis (TGA). Mass loss curves and kinetic parameters are well known, yet few studies report the performance and composition of pyrolytic products. Moreover, the reaction conditions found in TGA and other laboratory-scale devices used in these works are not representative of full-scale gasifiers, where high heating rates and good gas-solid contact are achieved (Cortazar et al., 2020). Induction heating is an interesting alternative without the shortcomings of other conventional methods. Shorter heating times, better control, and better temperature distribution could be achieved in comparison with electrical resistance based furnaces as seen in the work of (Mishra et al., 2019). Nevertheless, the literature regarding pyrolysis or gasification applications at laboratory scale using this method is very scarce.

This work focuses on the distribution and characterization of products of pyrolysis, representing the first decomposition step of gasification of SRF in a lab scale reactor, especially developed to emulate fast pyrolysis conditions. The conversion of "model materials", selected to represent the main fractions found in solid waste, is of particular interest. Results will contribute to the development and validation of accurate prediction models, providing a better insight on the influence of feedstock on the reaction products.

\subsection{Abbreviations}

- MSW: Municipal Solid Waste

- RDF: Refuse Derived Fuel

- SRF: Solid Recovered Fuel

TGA: Thermogravimetric Analysis

LDPE: Low-Density Polyethylene

PET: Polyethylene Terephthalate

FID: Flame Ionization Detector

- NDIR: Non-Dispersive Infrared Detector

\section{MATERIALS AND METHODS}

\subsection{Feedstock}

A solid recovered fuel (SRF) sample produced from industrial and household waste was used for the tests. Typical discarded products from daily life were also collected and used as model materials.

Plastic samples consisted in low-density polyethylene (LDPE, referred here as PE), while polyethylene terephthalate (PET) was obtained from plastic water bottles. Wood sample consisted in pellets made from beech sawdust, and cardboard sample was obtained from packaging boxes. All materials were shredded up to particles between 1 and $3 \mathrm{~mm}$, and then characterized by ultimate and proximate analyses. Moisture content was determined at $105^{\circ} \mathrm{C}$ while ash content was measured at $815^{\circ} \mathrm{C}$ according to the ISO 1171 standard. Elemental composition $(\mathrm{C}, \mathrm{H}, \mathrm{N}, \mathrm{S})$ was determined with an ELEMENTAR analyzer. Composition and characteristics for each sample are listed in Table 1.

\subsection{Experimental setup and procedure}

A laboratory scale unit was specifically designed to conduct pyrolysis and gasification tests under some reaction conditions that are representative of fast pyrolysis in a fluidized bed reactor. These characteristics include high heating rates, a temperature range between 700 and $900^{\circ} \mathrm{C}$, and good gas/solid contact. Gas residence times inside the hot zone of the reactor are usually between 0.5 and 10 $s$ for bubbling fluidized bed reactors, and between 0.5 and $1 \mathrm{~s}$ for circulating fluidized bed reactors (Marshall et al., 2014). For the present device, a residence time between 1 and $5 \mathrm{~s}$ was targeted, long enough to enable significant volatile secondary reactions. The experimental setup is shown in Figure 1.

A stainless-steel tube $(560 \mathrm{~mm}$ in height, $30.15 \mathrm{~mm}$ in internal diameter) was externally heated by induction, with a water-cooled copper coil inductor (420 mm long) connected to a $12 \mathrm{~kW}$ electrical generator (HFP 12, EFD induction $\mathrm{Gmbh}$ ). Setpoint temperature was adjusted with a PID

TABLE 1: Characteristics of SRF and model materials.

\begin{tabular}{l|c|c|c|c|c}
\hline [wt\%] & SRF & PE & PET & Wood & Cardboard \\
\hline Moisture (ar.) & $5.17 \%$ & $0.29 \%$ & $0.5 \%$ & $7.30 \%$ & $6.69 \%$ \\
\hline Ash (db.) & $16.38 \%$ & $0 \%$ & $0 \%$ & $2.53 \%$ & $8.80 \%$ \\
\hline C (db.) & $48.00 \%$ & $85.50 \%$ & $63.00 \%$ & $46.80 \%$ & $43.60 \%$ \\
\hline H (db.) & $6.00 \%$ & $13.90 \%$ & $5.50 \%$ & $6.70 \%$ & $6.00 \%$ \\
\hline O (db by diff.) & $26.68 \%$ & $0.50 \%$ & $31.50 \%$ & $43.77 \%$ & $41.10 \%$ \\
\hline N (db.) & $1.33 \%$ & $0.02 \%$ & $0.02 \%$ & $0.02 \%$ & $0.03 \%$ \\
\hline S (db.) & $0.47 \%$ & $0.03 \%$ & $0.02 \%$ & $0.1 \%$ & $0.13 \%$ \\
\hline Cl (db.) & $1.14 \%$ & - & - & - & - \\
\hline
\end{tabular}

ar: as received, $d b$ : dry basis

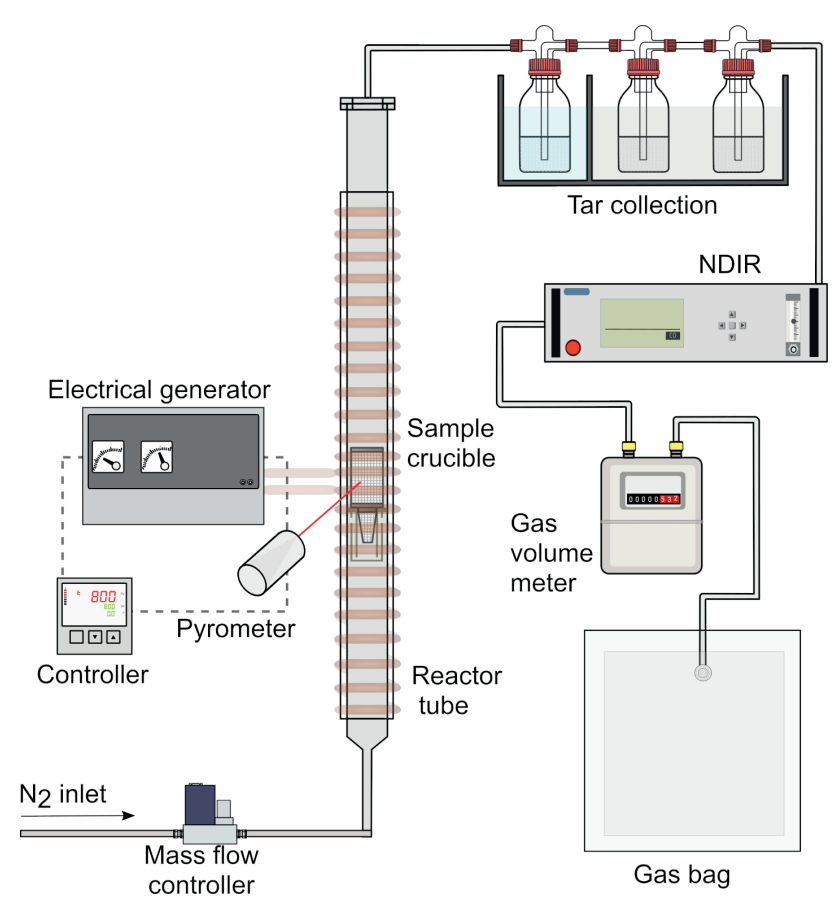

FIGURE 1: Schematic diagram of the lab scale device. 
controller (GEFRAN 2500), connected to a two-color optical pyrometer (Impac IGAR 6). Its spot is pointing on the tube surface, at the height of the sample crucible.

The crucible was filled with 2 to $3 \mathrm{~g}$ of dried feedstock $\left(24 \mathrm{~h}\right.$ at $\left.105^{\circ} \mathrm{C}\right)$ and placed in the isothermal zone of the reactor. $\mathrm{N}_{2}(0.5 \mathrm{~L} / \mathrm{min})$ was used to flush the entire system and to carry the produced volatiles. The reactor was heated up to $800^{\circ} \mathrm{C}$, with a heating rate of about $70^{\circ} \mathrm{C} / \mathrm{s}$, and then held at this temperature for about 20 minutes. Previous tests showed that the temperature was homogeneous in the sample, with a maximum temperature difference of $10^{\circ} \mathrm{C}$.

Produced gases flowed upwards in the reactor top section and the outlet line, both traced and insulated to keep temperature above $250^{\circ} \mathrm{C}$, and thus to prevent tar and water condensation before reaching the tar traps. Five gas washing bottles filled with 2-propanol were used to collect gas condensable species (water and tar) present in the stream. Glass wool and glass beads were used to improve the contact area between the gas and the solvent. The first two bottles were installed in an ice bath at $0^{\circ} \mathrm{C}$, while the other three were immersed in a carbonic ice and 2-propanol bath at $-70^{\circ} \mathrm{C}$. Collected condensable hydrocarbons were sampled and subsequently analyzed by using a gas chromatograph system. Species were identified by the means of mass spectrometry coupled with a flame ionization detector for the quantification (GC-FID, Agilent 7890A).

Non-condensable gases were analyzed online using a Non-Dispersive Infrared Detector (NDIR Model 30, CAI), able to record $\mathrm{CO}, \mathrm{CO}_{2}$ and $\mathrm{CH}_{4}$ concentrations every $1 \mathrm{~s}$. The volume of the outlet gas was measured by a gas meter placed at the outlet of the NDIR analyzer. Permanent gases were then collected in a Tedlar bag to be further analyzed by micro gas chromatography (Agilent 3000A). Remaining solid products in the sample crucible were weighed and collected once the reactor had cooled down to ambient temperature.

\section{RESULTS AND DISCUSSION}

\subsection{Carbon distribution}

The carbon distribution among the pyrolysis products, namely gas, tar and char, is shown in Figure 2. These yields are calculated as the ratio of carbon in each product per mass of initial carbon in the dry ash free feedstock. Considered gas species consisted in $\mathrm{H}_{2}, \mathrm{CO}, \mathrm{CO}_{2}, \mathrm{CH}_{4}, \mathrm{C} 2$ hydrocarbons $\left(\mathrm{C}_{2} \mathrm{H}_{4}, \mathrm{C}_{2} \mathrm{H}_{6}, \mathrm{C}_{2} \mathrm{H}_{2}\right), \mathrm{C} 3$ hydrocarbons $\left(\mathrm{C}_{3} \mathrm{H}_{6}, \mathrm{C}_{3} \mathrm{H}_{8}\right)$, benzene $\left(\mathrm{C}_{6} \mathrm{H}_{6}\right)$ and toluene $\left(\mathrm{C}_{7} \mathrm{H}_{8}\right)$. The tar fraction is defined here as all condensable organic compounds with a higher molecular weight than toluene.

For every feedstock, carbon was mostly converted into gas, as the high temperature and heating rate enhanced the thermal degradation of primary volatiles (E. C. Efika et al., 2015). The carbon fraction in solid was under $2 \mathrm{wt} \%$ for $\mathrm{PE}$,and corresponds to carbon deposits in the walls of the sample crucible. Cellulosic materials (wood and cardboard) showed high $\mathrm{C}$ content in the solid fraction. Char yield was greater in the former case, since wood has a higher lignin content than cardboard, which is composed mostly of cellulose. Lignin presents a more complex molecular structure and high fixed carbon content, which makes it more thermally stable (Muley et al., 2016). The highest fractions of carbon in tar were found for SRF (12 wt\%), followed by PE (10.7 wt\%) and PET (7.4 wt\%). Plastic content in waste fuels improves gas yield, but also increases tar content in syngas as observed here and also by other authors (Wilk \& Hofbauer, 2013; Zaccariello \& Mastellone, 2015). C-balance closure ranged between 75 and $90 \%$. Deviations could be attributed to the volatilization of light compounds from the tar traps, and undetected species that were not quantified in the FID analysis.

\subsection{Solid residue (char)}

The chemical composition of the solid residue obtained after pyrolysis tests is listed in Table 2 . The oxygen

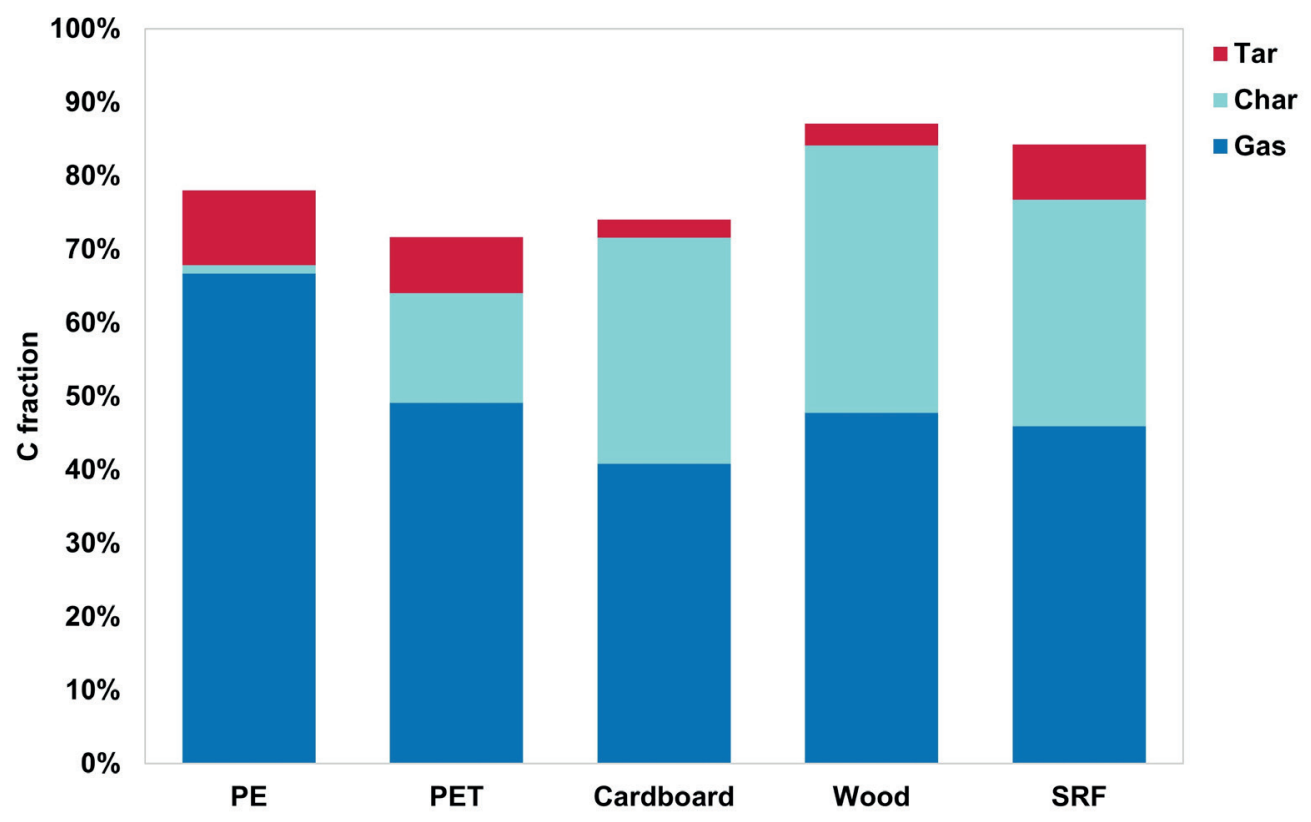

FIGURE 2: Carbon distribution from SRF and its components to pyrolysis products at $800^{\circ} \mathrm{C}$. 
content was calculated by difference, and the ash content was determined also at $815^{\circ} \mathrm{C}$. No char was observed in the case of PE. The solid residue from SRF and cardboard pyrolysis showed the lowest amount of carbon, and high ash contents, which are related to the inorganics and inert materials from the original feedstock.

\subsection{Gas composition}

Yield and volumetric composition of the produced gases from SRF and model materials pyrolysis, are displayed in Table 3. Low density polyethylene showed the highest yield of gas. Its long-branched structure, follows a random chain scission mechanism during its devolatilization, giving high yields of hydrogen, light olefins (mostly C2 hydrocarbons) and no char as stated by other authors (Al-Salem et al., 2017; Block et al., 2019). Gas yields values were similar for SRF and the other studied materials.

$\mathrm{CO}$ and $\mathrm{CO}_{2}$ were the main produced gas species in PET pyrolysis due to presence of oxygen groups from its monomer. Hydrocarbon production was much lower compared to PE, as observed also in the work of (Honus et al., 2018). Biogenic feedstock (wood, cardboard), which have an important $\mathrm{O}$ content, yielded the highest concentrations of oxygenated gases. $\mathrm{CO}$ and $\mathrm{CO}_{2}$ contents were higher for cardboard case, while methane content was higher for wood. Raw materials used in the production of paper and cardboard are submitted to delignification processes, so their cellulose content can go up to $99 \%$ (Runchal et al., 2018). (Yang et al., 2007), suggested that cracking of carbonyl functional groups of cellulose gave high $\mathrm{CO}$ yields, while the degradation of aromatic rings and methoxyl groups in lignin enhanced $\mathrm{CH}_{4}$ yields.

(Win et al., 2020) conducted flash pyrolysis experiments of wood pellets and polyethylene in an electric furnace at $900^{\circ} \mathrm{C}$. In their results, yield of $\mathrm{H}_{2}$ was higher for wood pellet $(25 \% \mathrm{vol})$ than that for polyethylene $(20 \% \mathrm{vol})$, which differs from the findings presented here. They attributed those results to water-gas reactions, enhanced from the moisture content of wood pellets. In our study, samples were dried prior to the experiments, and pyrolysis temperature was lower, hence these reactions were not favored. Yields of methane and ethylene were close to our results for both materials.

Regarding the composition of the gas produced in the pyrolysis of the SRF, CO was the major gas component (30\%), followed by $\mathrm{CH}_{4}(23 \%)$ and $\mathrm{H}_{2}(22 \%)$. Gas distribution after SRF pyrolysis was intermediate between different materials, being plastics responsible for the high yields of $\mathrm{CH}_{4}$ and $\mathrm{C}_{2}$ hydrocarbons while biogenic materials for the

TABLE 2: Chemical composition of the remaining solid residue after pyrolysis at $800^{\circ} \mathrm{C}$

\begin{tabular}{|c|c|c|c|c|c|c|}
\hline wt $\%$ & $\% \mathrm{C}$ & $\% \mathrm{H}$ & $\% \mathbf{N}$ & $\% S$ & $\% 0$ & $\%$ Ash \\
\hline SRF & 35.97 & 1.32 & 0.96 & 1.05 & 11.60 & 49.1 \\
\hline PET & 85.17 & 1.49 & 0.22 & 0.14 & 12.98 & 0.98 \\
\hline Wood & 77.8 & 1.01 & 0.64 & 0.12 & 12.56 & 7.87 \\
\hline Cardboard & 45.13 & 0.73 & 0.37 & 0.14 & 14.3 & 39.33 \\
\hline PE & \multicolumn{6}{|c|}{ No char } \\
\hline
\end{tabular}

majority of oxygenated compounds. In general, the results found in this study followed the same trends observed in RDF pyrolysis tests conducted by other researchers at $800^{\circ} \mathrm{C}$ (Blanco et al., 2012; Daouk et al., 2018). It is known that the sample used here presented small fractions of other fossil derived materials such as PS and rubber, known for generate high amounts of methane during their pyrolysis (Zaini et al., 2019).

\subsection{Tar Composition and content}

The condensed tars were sampled and then analyzed by GC - FID. Quantified tar components were categorizedaccording to the classification system proposed by the Energy research Center of the Netherlands (ECN) (Devi et al., 2005). This classification is based on the solubility and condensation properties of the different tar compounds, which define the downstream treatment conditions. Tars are grouped in five classes (Table 4) depending on the number of aromatic rings.

As seen in Figure 3, tar content was much higher for plastics compared to lignocellulosic materials. When comparing the relative distribution of tar products by group, wood ,cardboard and PET showed high amounts of hetorocyclics (class 2), due to the presence of oxygenated compounds like phenol. Class 4 species content was higher for wood than for cardboard thanks to the presence of lignin, which is know to yield higher amounts of naphthalene (Zhou, Wu, et al., 2015). The primary products of PE pyrolysis consist mostly in alkenes, which react via Diels-Alder reactions producing single ring tar compounds like styrene and indene, and some 2- ring tars like naphthalene. PET monomer contains aromatic rings in its structure, which influence the formation of small amounts of heavy polyaromatic species (3 or more rings). SRF showed the highest tar yield, with high contents of heavy aromatics. This may be attributed to the presence of monomers with aromatic rings as evidenced with PET, but also others such as polystyrene.

\section{CONCLUSIONS}

Pyrolysis tests of SRF and selected modeled materials were carried out in a specifically developed induction heated reactor at $800^{\circ} \mathrm{C}$. The most common polymers in waste (PE and PET) were the model materials for the plastic fraction, while beech wood and cardboard were

TABLE 3: Gas composition from pyrolysis at $800^{\circ} \mathrm{C}$ of SRF and model materials.

\begin{tabular}{l|c|c|c|c|c}
\hline \% vol & SRF & PE & PET & Wood & Cardboard \\
\hline H2 & $22.1 \%$ & $29.5 \%$ & $24.8 \%$ & $19.8 \%$ & $20.5 \%$ \\
\hdashline CO & $30.1 \%$ & $0.6 \%$ & $31.6 \%$ & $44.2 \%$ & $48.7 \%$ \\
\hdashline CO2 & $9.8 \%$ & $0.4 \%$ & $22.9 \%$ & $12.0 \%$ & $12.7 \%$ \\
\hdashline CH4 & $22.4 \%$ & $25.6 \%$ & $8.6 \%$ & $18.2 \%$ & $13.2 \%$ \\
\hdashline C2 & $9.5 \%$ & $33.0 \%$ & $1.8 \%$ & $4.5 \%$ & $4.2 \%$ \\
\hdashline C3 & $0.1 \%$ & $1.4 \%$ & $0.0 \%$ & $0.0 \%$ & $0.1 \%$ \\
\hdashline BTX & $5.1 \%$ & $4.0 \%$ & $10.3 \%$ & $0.9 \%$ & $0.3 \%$ \\
\hline Gas yield[L/g daf] & 0.4215 & 0.7815 & 0.4463 & 0.4439 & 0.4203 \\
\hline
\end{tabular}




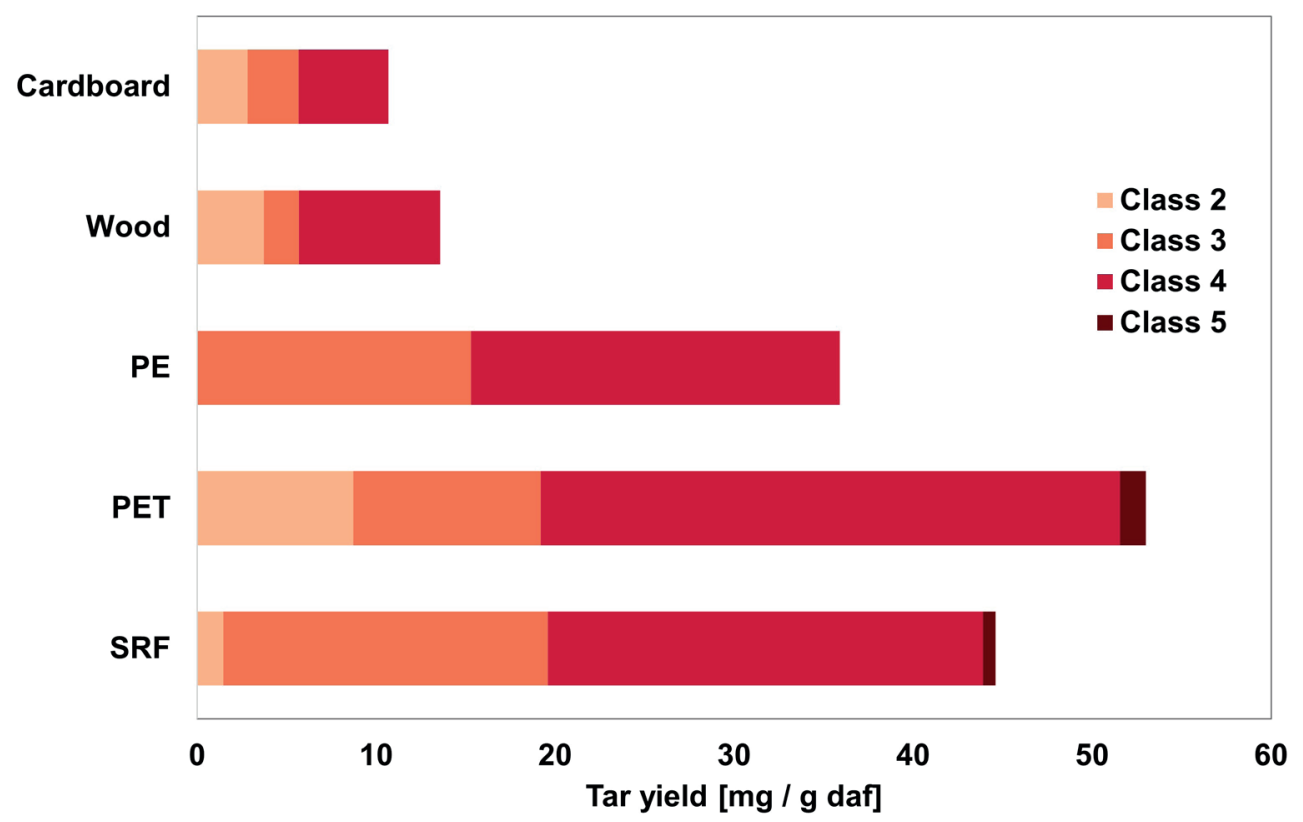

FIGURE 3: Composition of produced tar from the pyrolysis of SRF and model materials at $800^{\circ} \mathrm{C}$.

representative of lignocellulosic biomass. The reaction products were quantified and analyzed, and the composition of the produced gas was reported for each material. For all cases, carbon conversion to gas was higher than $40 \%$, as the high heating rates favored secondary reactions like the cracking of volatile products to lighter stable gases. Even if the elemental composition of some materials was very similar, differences were found in the gaseous and condensable products, showing that macromolecular structure can influence the final product distribution. These results will be helpful for the development of predictive models.

However, to have a better insight of the thermochemical conversion of solid waste and its derived fuels, additional studies must be conducted. Co-pyrolysis of waste is of particular interest, as synergetic effects may appear between the different materials modifying the final distribution of the products. Additional tests in partial oxidation conditions are also important to explore the impact of the gas phase reactions in the syngas and tar composition.

\section{REFERENCES}

Al-Salem, S. M., Antelava, A., Constantinou, A., Manos, G., \& Dutta, A. (2017). A review on thermal and catalytic pyrolysis of plastic solid waste (PSW). Journal of Environmental Management, 197, 177198. https://doi.org/10.1016/j.jenvman.2017.03.084

Blanco, P. H., Wu, C., Onwudili, J. A., \& Williams, P. T. (2012). Characterization of Tar from the Pyrolysis/Gasification of Refuse Derived Fuel: Influence of Process Parameters and Catalysis. Energy \& Fuels, 26(4), 2107-2115. https://doi.org/10.1021/ef300031j

Block, C., Ephraim, A., Weiss-Hortala, E., Minh, D. P., Nzihou, A., \& Vandecasteele, C. (2019). Co-pyrogasification of Plastics and Biomass, a Review. Waste and Biomass Valorization, 10(3), 483-509. https:// doi.org/10.1007/s12649-018-0219-8

Centi, G., \& Perathoner, S. (2020). Chemistry and energy beyond fossil fuels. A perspective view on the role of syngas from waste sources. Catalysis Today, 342, 4-12. https://doi.org/10.1016/j. cattod.2019.04.003

Chhabra, V., Bambery, K., Bhattacharya, S., \& Shastri, Y. (2020). Thermal and in situ infrared analysis to characterise the slow pyrolysis of mixed municipal solid waste (MSW) and its components. Renewable Energy, 148, 388-401. https://doi.org/10.1016/j.renene.2019.10.045

Cortazar, M., Lopez, G., Alvarez, J., Arregi, A., Amutio, M., Bilbao, J., \& Olazar, M. (2020). Experimental study and modeling of biomass char gasification kinetics in a novel thermogravimetric flow reactor. Chemical Engineering Journal, 396, 125200. https://doi. org/10.1016/j.cej.2020.125200

TABLE 4: Tar classification according to ECN.

\begin{tabular}{|c|c|c|c|}
\hline Tar class & Class Name & Properties & Compounds considered in this study \\
\hline 1 & GC-undetectable & Very heavy tars, cannot be detected by GC & \\
\hline 2 & Heretocyclic & Tars containing heteroatoms; highly water soluble compounds & Phenol, Benzofurane \\
\hline 3 & Light aromatics & $\begin{array}{l}\text { Usually light hydrocarbons with one ring; do not pose a problem regarding } \\
\text { condensability and solubility }\end{array}$ & $\begin{array}{l}\text { Ethylbenzene, Styrene } \\
\text { a-Methylstyrene, }\end{array}$ \\
\hline 4 & Light polyaromatics & $\begin{array}{l}\text { Two and three ring compounds; condense at low temperature even at very } \\
\text { low concentration }\end{array}$ & $\begin{array}{l}\text { Indene, Naphthalene, methylnaph- } \\
\text { thalene, Biphenyl, Acénaphty- } \\
\text { lene,Acénaphtene, Dibenzofurane, } \\
\text { Fluorene }\end{array}$ \\
\hline 5 & Heavy polyaromatics & $\begin{array}{l}\text { Larger than three-rings; these components condense at high temperatures at } \\
\text { low concentrations }\end{array}$ & Fluoranthene, pyrene \\
\hline
\end{tabular}


Daouk, E., Sani, R., Pham Minh, D., \& Nzihou, A. (2018). Thermo-conversion of Solid Recovered Fuels under inert and oxidative atmospheres: Gas composition and chlorine distribution. Fuel, 225, 54-61. https://doi.org/10.1016/j.fuel.2018.03.136

Devi, L., Ptasinski, K. J., Janssen, F. J. J. G., van Paasen, S. V. B., Bergman, P. C. A., \& Kiel, J. H. A. (2005). Catalytic decomposition of biomass tars: Use of dolomite and untreated olivine. Renewable Energy, 30(4), 565-587. https://doi.org/10.1016/j.renene.2004.07.014

Efika, C. E., Onwudili, J. A., \& Williams, P. T. (2018). Influence of heating rates on the products of high-temperature pyrolysis of waste wood pellets and biomass model compounds. Waste Management, 76 497-506. https://doi.org/10.1016/j.wasman.2018.03.021

Efika, E. C., Onwudili, J. A., \& Williams, P. T. (2015). Products from the high temperature pyrolysis of RDF at slow and rapid heating rates. Journal of Analytical and Applied Pyrolysis, 112, 14-22. https:// doi.org/10.1016/j.jaap.2015.01.004

Esmaeili, V., Ajalli, J., Faramarzi, A., Abdi, M., \& Gholizadeh, M. (2020). Gasification of wastes: The impact of the feedstock type and cogasification on the formation of volatiles and char. International Journal of Energy Research, n/a(n/a), Article n/a. https://doi. org/10.1002/er.5121

Garcés, D., Díaz, E., Sastre, H., Ordóñez, S., \& González-LaFuente, J. M. (2016). Evaluation of the potential of different high calorific waste fractions for the preparation of solid recovered fuels. Waste Management, 47, 164-173. https://doi.org/10.1016/j.wasman.2015.08.029

Honus, S., Kumagai, S., Fedorko, G., Molnár V., \& Yoshioka, T. (2018) Pyrolysis gases produced from individual and mixed PE, PP, PS, PVC, and PET-Part I: Production and physical properties. Fuel, 221, 346-360. https://doi.org/10.1016/j.fuel.2018.02.074

Hwang, I.-H., Kobayashi, J., \& Kawamoto, K. (2014). Characterization of products obtained from pyrolysis and steam gasification of wood waste, RDF, and RPF. Waste Management, 34(2), 402-410. https:// doi.org/10.1016/j.wasman.2013.10.009

Kaza, S., Yao, L., Bhada-Tata, P., \& Van Woerden, F. (2018). What a Waste 2.0: A Global Snapshot of Solid Waste Management to 2050 The World Bank. https://doi.org/10.1596/978-1-4648-1329-0

Marshall, A. J., Wu, P. F., Mun, S.-H., \& Lalonde, C. (2014). Commercial application of pyrolysis technology in agriculture. American Society of Agricultural and Biological Engineers Annual International Meeting 2014, ASABE 2014, 5, 3868-3886.

Meng, A., Chen, S., Long, Y., Zhou, H., Zhang, Y., \& Li, Q. (2015). Pyrolysis and gasification of typical components in wastes with macro-TGA Waste Management, 46, 247-256. https://doi.org/10.1016/j.wasman.2015.08.025

Mishra, H., Patidar, B., Pante, A. S., \& Sharma, A. (2019). Mathematica modelling, simulation and experimental validation of resistance heating and induction heating techniques for E-waste treatment. IET Electric Power Applications, 13(4), 487-493. https://doi. org/10.1049/iet-epa.2018.5535
Muley, P. D., Henkel, C., Abdollahi, K. K., Marculescu, C., \& Boldor, D. (2016). A critical comparison of pyrolysis of cellulose, lignin, and pine sawdust using an induction heating reactor. Energy Conversion and Management, 117, 273-280. https://doi.org/10.1016/j. enconman.2016.03.041

Pasel, C., \& Wanzl, W. (2003). Experimental investigations on reactor scale-up and optimisation of product quality in pyrolysis of shredder waste. Fuel Processing Technology, 80(1), 47-67. https://doi. org/10.1016/S0378-3820(02)00187-X

Runchal, A. K., Gupta, A. K., Kushari, A., De, A., \& Aggarwal, S. K. (2018). Energy for Propulsion A Sustainable Technologies Approach. Springer Singapore: Imprint: Springer. https://link.springer. com/10.1007/978-981-10-7473-8

Saghir, M., Rehan, M., \& Nizami, A.-S. (2018). Recent Trends in Gasification Based Waste-to-Energy. In Y. Yun (Ed.), Gasification for Low-grade Feedstock. InTech. https://doi.org/10.5772/intechopen.74487

Solid Recovered Fuels: Specification and Classes: CEN/TS 15359 Technical Specification : English Version. (2006). European Committee for Standarization.

Wilk, V., \& Hofbauer, H. (2013). Conversion of mixed plastic wastes in a dual fluidized bed steam gasifier. Fuel, 107, 787-799. https://doi. org/10.1016/j.fuel.2013.01.068

Win, M. M., Asari, M., Hayakawa, R., Hosoda, H., Yano, J., \& Sakai, S. I. (2020). Gas and tar generation behavior during flash pyrolysis of wood pellet and plastic. Journal of Material Cycles and Waste Management, 22(2), 547-555. https://doi.org/10.1007/s10163019-00949-8

Yang, H., Yan, R., Chen, H., Lee, D. H., \& Zheng, C. (2007). Characteristics of hemicellulose, cellulose and lignin pyrolysis. Fuel, 86(12), 1781-1788. https://doi.org/10.1016/j.fuel.2006.12.013

Zaccariello, L., \& Mastellone, M. L. (2015). Fluidized-Bed Gasification of Plastic Waste, Wood, and Their Blends with Coal. Energies, 8(8), 8052-8068. https://doi.org/10.3390/en8088052

Zaini, I. N., García López, C., Pretz, T., Yang, W., \& Jönsson, P. G. (2019) Characterization of pyrolysis products of high-ash excavatedwaste and its char gasification reactivity and kinetics under a steam atmosphere. Waste Management, 97, 149-163. https://doi org/10.1016/j.wasman.2019.08.001

Zhou, H., Long, Y., Meng, A., Li, Q., \& Zhang, Y. (2015). Thermogravimetric characteristics of typical municipal solid waste fractions during co-pyrolysis. Waste Management, 38, 194-200. https://doi. org/10.1016/j.wasman.2014.09.027

Zhou, H., Wu, C., Onwudili, J. A., Meng, A., Zhang, Y., \& Williams, P. T. (2015). Polycyclic aromatic hydrocarbons (PAH) formation from the pyrolysis of different municipal solid waste fractions. Waste Management, 36, 136-146. https://doi.org/10.1016/j.wasman.2014.09.014 